\title{
Numerical Investigation of Heat Transfer Rate in Helically Coiled Pipe Using A1203/Water Nanofluid
}

\author{
Ahmed F. Hasan ${ }^{1, *}$, Syed Tauseef Hossain ${ }^{2}$ \\ ${ }^{1}$ Department of Materials Engineering, University of Diyala, Baquba 32001, Iraq \\ ${ }^{2}$ Department of Mechanical, Materials and Manufacturing, University of Nottingham, Nottingham, UK.
}

\section{ARTICLE INFO}

Article history:

Received 5 November 2020

Accepted 28 November 2020

Keywords: Nanofluid, pure water, Heat transfer rate, Helically coiled pipe, CFD model

\begin{abstract}
Nanofluid materials play an important role in the industry nowadays, which has drawn the attention of researchers to enhance the characteristics of the heat transfer of the fluids in the coiled shape heat exchangers. The effect of using Al2O3/water Nano fluid on the characteristic of the heat transfer rate inside the helically coiled pipe was numerically studied at different Reynolds numbers. Moreover, fluid flow analyses were investigated numerically in terms of pressure and velocity profile. The heat transfer enhancement using this Nano fluid has been studied and then compared to pure water at Reynolds number values of 200,600 , and 1500 respectively. The results showed that a reduction in the temperature of the outer wall pipe when A12O3/water Nano fluid was applied particularly at a low Reynolds number compared to pure water. Generally speaking, it has been seen that the reduction in the temperature profile is much better than the high Reynolds number.
\end{abstract}

\section{Introduction}

The energy crisis is considered one of the most important problems facing the world due to the large and continuous increase in consumption rates and the increasing shortage of traditional energy resources and high prices. Therefore, researchers are deliberately aimed to increase the efficiency of heat exchange systems by reducing pressure loss and minimizes their energy consumption rates.

A variety of types of heat exchangers are available. Every form has its advantages and disadvantages. Active and passive methods are widely used to improve the coefficient of heat transfer [1]. In a heat exchanger, heat transfer generally includes convection in each fluid and conduction through a wall which separates the two fluids.
Helically coiled tube is one of the most common forms of passive technology that produces comparatively more compact heat exchangers used in a wide variety of heat transfer applications, such as food processing, refrigeration and air conditioning systems, and hydrocarbon processing,[12] due to high efficiency and compact size compared with straight tubes.

The curved duct problem was first proposed mathematically by Dean (1927) [11] under clearly described flow conditions. For the fully developed flow within a curved circular tube, the presence of a pair of counter-rotating vortices as a secondary flow in the curved tube was confirmed [7]. Due to the presence of imbalance centrifugal forces, these two vortices have developed a secondary flow called Dean

\footnotetext{
*Corresponding author.

E-mail address: ahmedfalh.eng@gmail.com

DOI: $10.24237 /$ djes.2020.13404
}

This work is licensed under a Creative Commons Attribution 4.0 International License. 
vortices (Reynolds number $\mathrm{x} \sqrt{\frac{\text { dinerer }}{\text { Dcöl }}}$ ) as shown in

Figure 1 [6]. Besides, the rate of heat transfer increases compared to the straight pipe caused by the increased mixing of flow generated by the secondary flow.

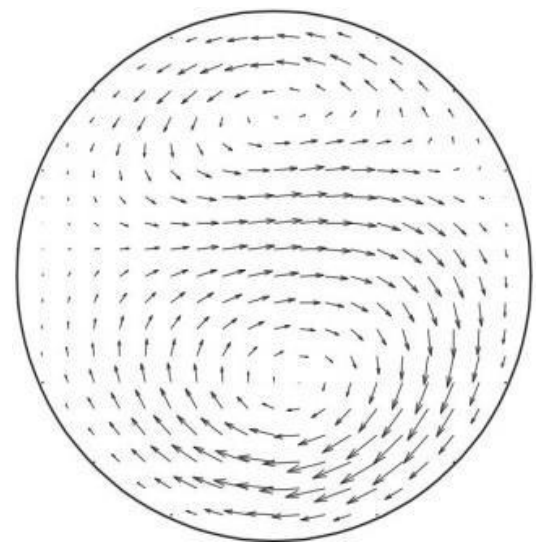

Fig 1. Dean vortices [8]

The variations in the local Nusselt number along the length and diameter of the helical pipes were observed and analyzed [16]. In addition to the effect of varying geometrical parameters on the rate of heat transfer, numerical simulation analysis of the fluid flows was also conducted by changing these parameters. Such parameters are the diameter of the pitch circle (curvature ratio), pitch, and diameter of the pipe. Three different coils have been tested while maintaining pitch and pipe diameter constant [19]. The pitch circle diameter of the coiled pipe was found to have a strong effect on the flow structure. Moreover, regarding the pitch size, zero pitch size means no secondary flow and consequently, the Nusselt number is approximately identical [16]. However, as the pitch increases, this allows triggering of the secondary flow which plays a vital role in enhancing the heat transfer rate.

A correlation between the Reynold numbers, the Nusselt number, and the Prandtl number used to test the heat transfer rate at different coiled pipe cross-sections were determined using experimental analysis [5]. While several studies had previously been carried out [21] [23] [20] for the same purpose as stated above, a study that would cover a wide range of helically coiled pipes to acquire a deeper understanding of the local heat transfer properties in all directions was still required.

$(N u)\left(P r^{-0.4}\right)=0.0456\left(\operatorname{Re}^{0.8}\right) \stackrel{\underset{D}{d}}{-0.21}$

This equation was compared to several other equations to demonstrate an increase in the estimation of the average coefficient of heat transfer. It was suggested that as the number of Reynolds increases, the turbulent boundary layer becomes less dense and this, in effect, decreases the secondary flow's contribution to enhancing the heat transfer efficiency. Besides, the average heat transfer coefficient profile on the pipe's circumferential cross-section is approximately symmetric.

Due to their high thermal conductivity, porous media and Nano fluid have been used to increase the heat transfer rate concerning the impact of base fluid such as water. Improvement in heat transfer due to the use of $\mathrm{CuO}$ /water Nano fluid in terms of heat transfer rate was stated [24].

It has been also shown that $\mathrm{Al} 2 \mathrm{O} 3$ Nano fluid had a better thermal conductivity and diffusivity as its volume of fraction increased. In addition to the enhancement of the thermal conductivity, a volume of a fraction of $2.5 \%$ (nanoparticle/base fluid) can also lead to improving convective heat transfer coefficient at a high flow rate [2] [13-15]. Therefore, many numerical and experimental studies have reported that using a base fluid with nanoparticles increased the thermal performance compared to a conventional fluid and this enhancement increase as the concentration of the particles increased [4]. However, a recent numerical study [10] showed that the nanoparticle size has no major impact on the properties of the heat transfer.

However, despite the huge number of studies concerning the helically coiled pipes at various parameters, there is a lack of relation between the working fluid and heat transfer rate at constant heat flux [11]. Experimental studies of the flows within the helically coiled pipe are complicated and, particularly for small diameters, may also be expensive. This allows the researcher to use the CFD to study and evaluate the flow structure of both laminar and 
turbulent flow inside the coiled tubing. Therefore, the current paper will Evaluate and validate the flow structure inside the coiled pipe compare to other similar numerical work done by Anwer [11]. Moreover, once the numerical simulation was validated, the effect of using A12O3 Nano fluid on the heat trader rate compared to pure water at constant heat flux was performed.

\section{Numerical modelling methodology}

In the current study, two models were built. The first one has used for the validation of the predicted results in terms of fluid flow which was the isothermal base model. While the second one has been developed to predict the fluid flow behavior and thermal performance of the Nanofluid that being utilized which is essentially a thermal base model. Here, a commercially CFD code has been used to simulate a three-dimensional model of the fluid flow behavior in the helical tube. ANSYS Workbench 18.1 was used for computational modeling, which includes drawing geometry and build the mesh then after was used to run the case via FLUENT. CFD post was utilized to

extract the result and plot some graphs and contours.

\section{Geometry and mesh}

Three-dimensional models are created by using ANSYS Workbench R2018 as shown in Figure 2. The dimensions of the geometry are pipe diameter $5 \mathrm{~mm}$, coil diameter $40 \mathrm{~mm}$, and pitch diameter of $10 \mathrm{~mm}$. The total length of the helical tube is $252 \mathrm{~mm}$. The discretization process is one of the important steps in numerical modeling, which essentially depends on the mesh that needs to be created for the domain [1]. Appropriated mesh has been generated by using meshing software in ANSYS Workbench R2018. The model used a total number of hexahedral cells of 944228 , and a maximum Aspect Ratio of 4.38143. It is worth to mention that the selection of mesh was based on the recommendation of the study has been done by Anwar [11]. This kind of mesh has been shown a good result as it can be seen later in the next section. Indeed, good quality of mesh has the capability of captures many important features that need to be investigated.

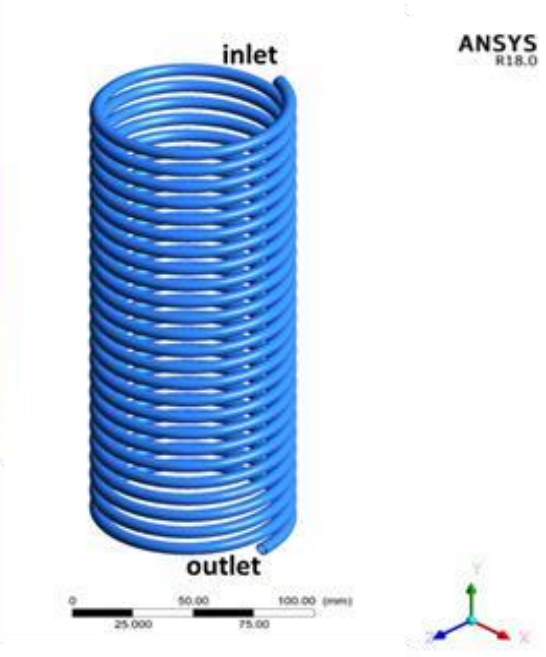

Fig 2. Models geometry with its mesh that has been used

\section{Boundary conditions and numerical solution}

It is well known that the CFD code since it has been invented before four decades showed a significant advantage in terms of fluid flow problems. The main governing equations are normally solved based on the finite volume method (FVM). These equations are continuity, momentum, and energy equations which are combined in one form that is solved in CFD code in a general formula called Navier-Stokes equations, further details of these equations can be found elsewhere [13]. 
Two materials have been considered the first one was water and the second one was Nano fluid and a single-phase base model was used for both fluid cases; the details of the fluid materials are presented in Table 1.

Table 1. Physical properties of the fluid being considered

\begin{tabular}{ccccc}
\hline Materials & $\begin{array}{c}\text { Thermal conductivity } \\
(\mathbf{W} / \mathbf{m} . \mathbf{K})\end{array}$ & $\begin{array}{c}\text { Specific heat } \\
(\mathbf{J} / \mathbf{k g} . \mathbf{K})\end{array}$ & $\begin{array}{c}\text { Density } \\
(\mathbf{k g} / \mathbf{m 3})\end{array}$ & $\begin{array}{c}\text { Dynamic viscosity } \\
(\mathrm{kgm} . \mathrm{sec})\end{array}$ \\
\hline Copper (Tube) & 387.6 & 381 & 9878 & - \\
Water & 0.607 & 4180 & 998.2 & 0.001003 \\
Nano fluid & 0.6113 & 4149.40 & 1004.7 & 0.00102 \\
$\mathbf{A l}_{2} \mathbf{O}_{3} /$ water & & & & \\
\hline
\end{tabular}

It is worth to mention that the density and viscosity values of the Nano fluid have been calculated according to the formula, which is listed below in this section. The effective density ( $\rho n f)$, heat capacitance $(\rho \mathrm{Cp})$ nf, thermal conductivity $(\mathrm{Knf})$ and dynamic viscosity $(\mu \mathrm{nf})$ of the Nano fluid for two different Nano fluids that are applied in this study, such as Al2O3$\mathrm{H} 2 \mathrm{O}$ are presented by the following equations [26]:

$$
\begin{aligned}
& \rho_{n f}=(1-\emptyset) \rho_{f}+\emptyset \rho_{n p} \\
& \left(\rho C_{P}\right)_{n f}=(1-\emptyset)\left(\rho C_{p}\right)_{f}+\emptyset\left(\rho C_{P}\right)_{n p} \\
& k_{n f}=k_{\text {Stati̊c }}+k_{\text {Browainn }} \\
& k_{\text {Stat }{ }^{\circ} \mathrm{C}}=k_{f}\left(\frac{\left(k_{\underline{n} \underline{p}}+2 k_{f}\right)-2 \emptyset\left(k_{f}-k_{\underline{n p}}\right)}{\left.k_{n p}+2 k_{f}\right)+\emptyset\left(k_{f}-k_{n p}\right)}\right) \\
& k_{\text {Browi̊nan }}=5 \times 10^{4} \beta \emptyset \rho C_{p f} \sqrt{\frac{k_{b} T}{\rho_{p} d_{p}}} f(T, \emptyset) \\
& f(T, \varnothing)=\left(2.8217 \times 10^{-2} \emptyset+3.917 \times 10^{-3}\right)\left(\frac{T}{T_{\circ}}\right)+ \\
& \left(-3.0669 \times 10^{-2} \emptyset-3.91123 \times 10^{-3}\right) \\
& \frac{\mu_{n f}}{\mu_{f}}=\frac{1}{1-34.87\left(\frac{d_{n p}}{d_{f}}\right)^{-0.3} \emptyset^{1.03}}
\end{aligned}
$$

The boundary conditions play an important role in any numerical model which is set to represent the physical situation of any fluid case, to capture the fluid behavior (Hasan, Bennett, and Shipway 2015). In the current study the main boundary conditions were:

Fluid inlet with four Reynolds number $(\mathrm{Re})$ that used to set velocity value for each case as shown in Table 2, it is important to highlight that for the validation model and heat model there was a slight difference in Re value for both types of fluid being considered but both cases were under laminar behavior. This was due to the available data for this Nano fluid being considered. In the case of validation, the Re number values that have been considered have ranged from 500 to 2000 as can be seen in Table 2 . In contrast, with case two the study used 200,
600, and $1500 \mathrm{Re}$ values. Outlet pressure was set for the outlet side and the wall side with noslip boundary conditions was set for the pipe side, this was for the validation model. On the other hand, in the heat model, the pipe thickness was taken into account in the solution.

For the second model, the energy equation was activated to predict the temperature distribution on the domain. A constant heat flux value was used with a $6000 \mathrm{~W} / \mathrm{m} 2$ which has been applied at the outer wall of the helical tube. Semi-Implicit Method (SIMPLE) has been used to satisfy the continuity equation for the pressure linked with the second-order option. considered for both momentum and energy equations.

Table 2. Velocity inlet and Re number for the laminar flow

\begin{tabular}{cc}
\hline Inlet velocity $(\mathbf{m} / \mathbf{s e c})$ & Reynolds Number \\
\hline 0.100481 & 500 \\
0.150721 & 750 \\
0.200962 & 1000 \\
0.251202 & 1250 \\
0.301443 & 1500 \\
0.351683 & 1750 \\
0.401923 & 2000
\end{tabular}

\section{Results and discussion}

The validation process is considered one of the most important steps in any numerical simulation, it can provide a kind of certainty and reliability of any model that can be utilized in any parametric study that needs to be conducted in the future (Mahdi et al. 2019). Therefore, in the current study, the variation of the Reynolds number versus the wall shear stress without Nano fluid was validated against [12] as shown in Figure3. Indeed, further work is a need in terms of thermal model validation, however, the authors will tend to do this stuff in the future. 
To do this important step, two surface planes have been created in the helical coil pipe, typically they were a cross-section plane. Which were located in the fluid domain where the fully developed zone, essentially, the first one in the mid-region of the coil, and the second one was before the outlet as recommended by the works of [3]. The outcome of this plane was to determine the pressure differences in order to compute the wall shear stress, further details for this calculation can be found elsewhere [3]. The current numerical results were found to be following the results published by Anwer [11] with less than average differences of $7 \%$ (error margin).

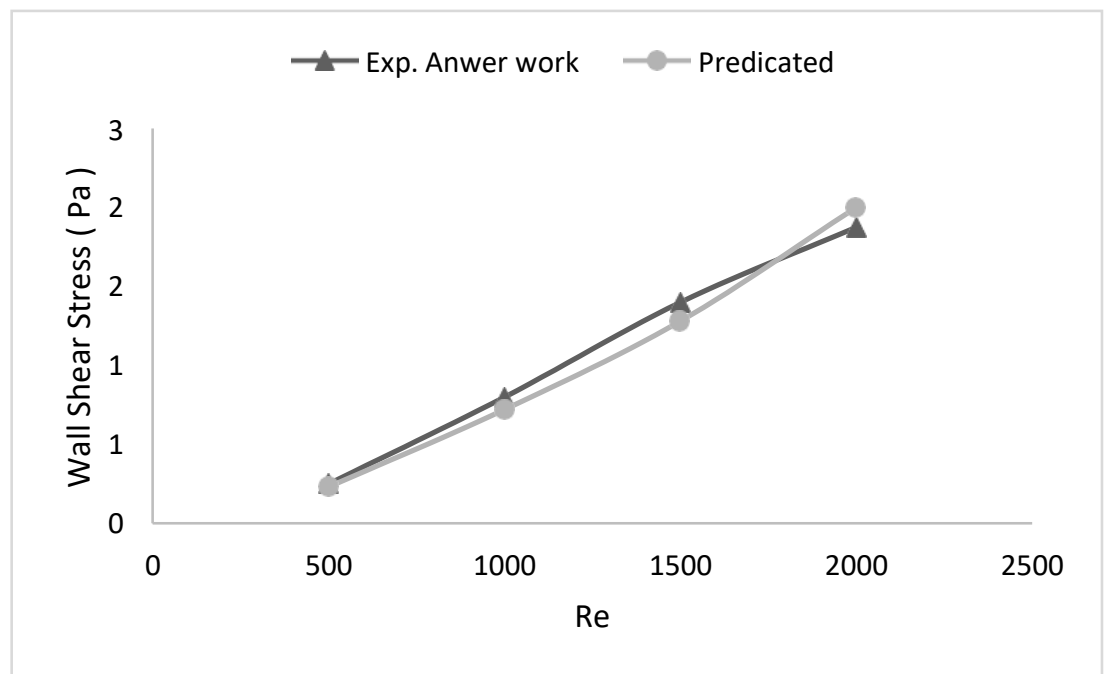

Fig 3. Predicted and experimental values of wall shear stress against Re no.

The Figure shows the temperature distribution of the outlet surface when A12O3/water Nano fluid was applied. Figure 4 clearly showed the data were extracted from a line that was created at the outlet surface from the outer edge of the pipe to the pipe centre (essentially, they have measured from 37 to 40 $\mathrm{mm}$ respectively). The results showed that utilizing Nano fluid increases heat transfer by decreasing the temperature of the outer surface compared to pure water. In comparison to pure water, nanofluid reduce the temperature from $728 \mathrm{~K}$ to $722 \mathrm{~K}$. Moreover, Figure 5 shows the temperature, velocity, and pressure contours at the specified plane. The figure clearly showed that the temperature is lower when the Nano fluid used which more likely due to the higher thermal conductivity of the nanoparticles compared to pure water.
It can be noticed that there is an improvement in the case of using Nano fluid, it can be argued this because the secondary flow that produced from better thermal conductivity obtained when Nanofluid being used. The secondary flow plots are shown in Figure 10, this figure can provide more insight which can provide a better understating for the velocity effect in such cases. Another key point that has been gained from the figure of the pressure contour is Nano fluid increases the heat transfer coefficient due to the relationship between Nano fluid viscosity with temperature. In which previously has been documented by Kumar and Chandrasekar [17] when their study showed that using Nano fluid causes more pressure drop than in the case of using pure water. 


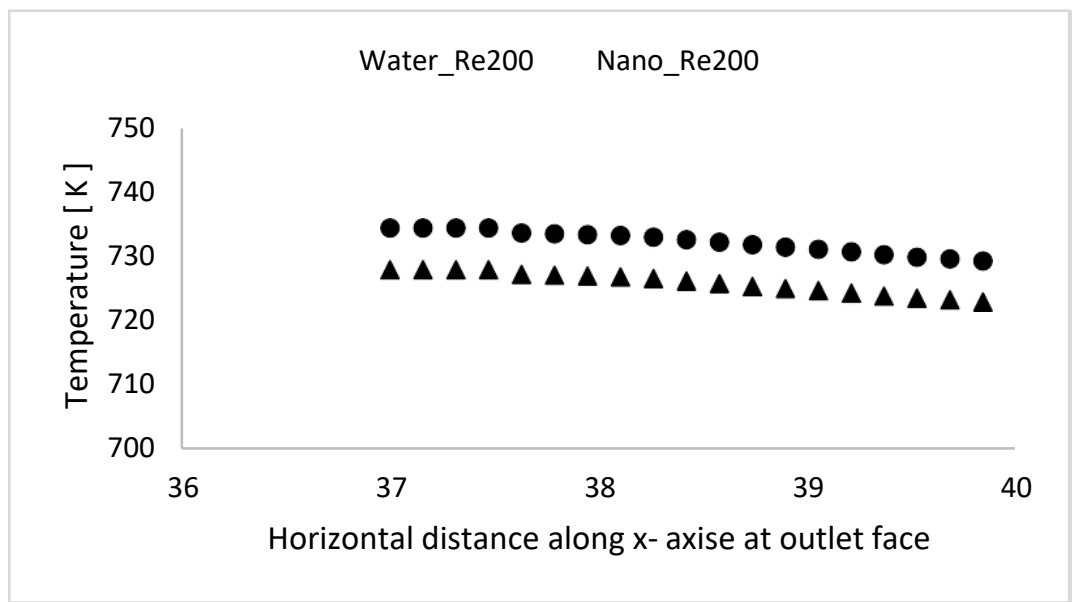

Fig 4. Temperature distribution versus surface outlet pipe at $\mathrm{Re}=200$

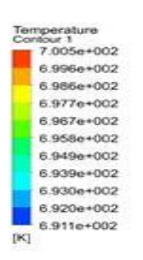
Pure water

Nanofluid
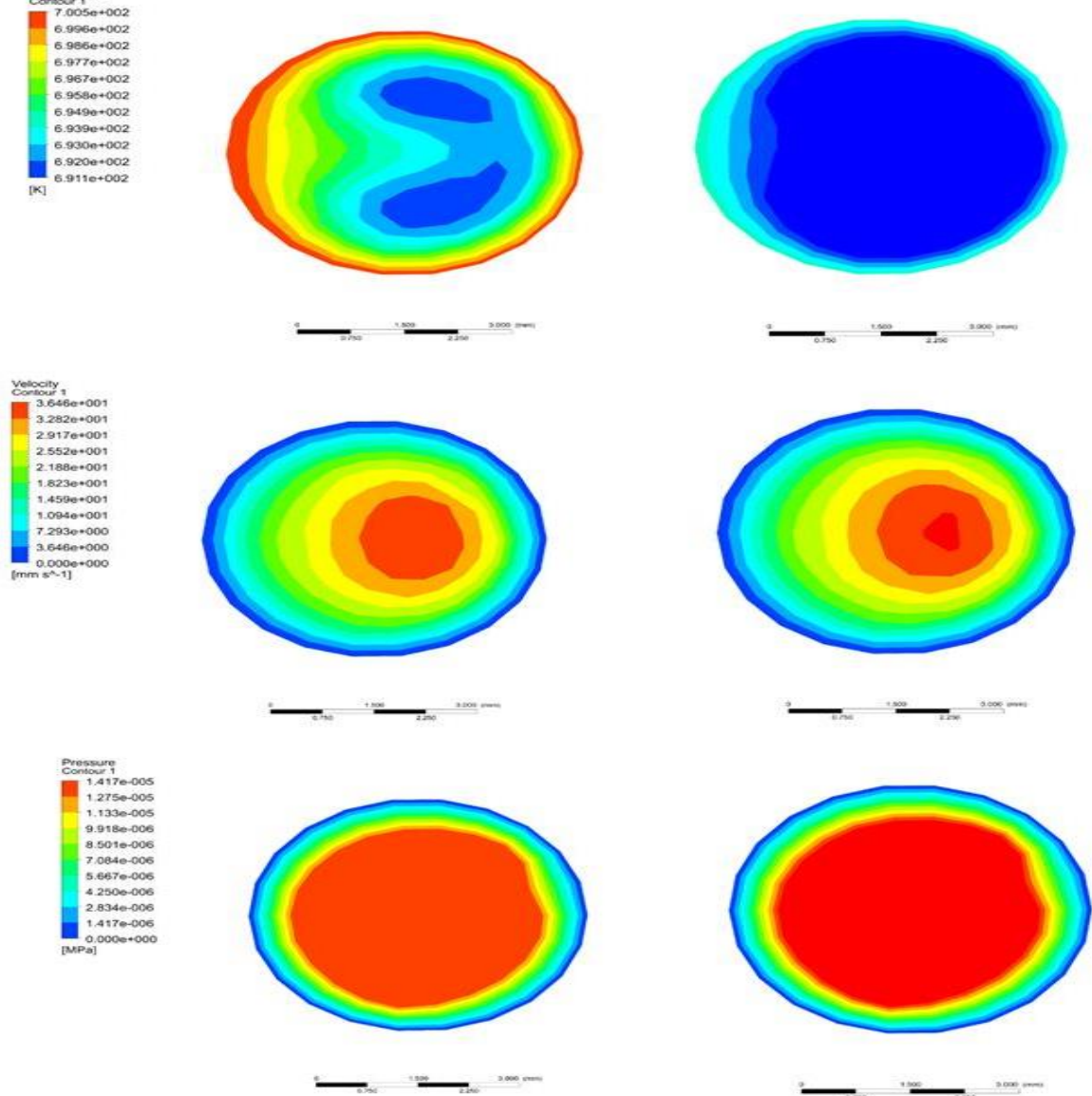

Fig 5. Temperature, velocity, and pressure contours at $\mathrm{Re}=200$ using Nano fluid and pure water

As can be seen in Figures 6 and 7, increasing the Re number from 200 to 600 , reduces the differences in temperature between Nano fluid and pure water. This is due to that increasing the Re number leads to higher mixing between water and nanoparticles which leads to lower thermal conductivity.

Increasing Reynold's number to $\mathrm{Re}=600$ reduces the discrepancies between Nano fluid and pure water on the temperature compared to the lower Reynolds number. However, as Reynolds number increased to $\operatorname{Re}=600 \mathrm{a}$ significant thermal performance enhancement (by about $40 \%$ ) was achieved in comparison to $\mathrm{Re}=200$. This is more likely due to the higher velocity which keeps it the same and is seen in Figure 7 which reduces the surface friction and hence increasing the heat transfer rate.

In the case of increasing the Re value, the fluid velocity increased, and therefore the heat 
transfer will be improved. It can be argued that the flow path in the domain would increase the disturbance which causes increasing friction among the coil wall and the fluid. These factors ultimately lead to drops in the pressure value in the coil.
Therefore, with the same number of Reynolds $(\operatorname{Re}=600)$, in contrast with pure water, the application of Nano fluid also has a lower temperature such that a significant reduction in the temperature distribution is seen as the application of A12O3/water Nano fluid.

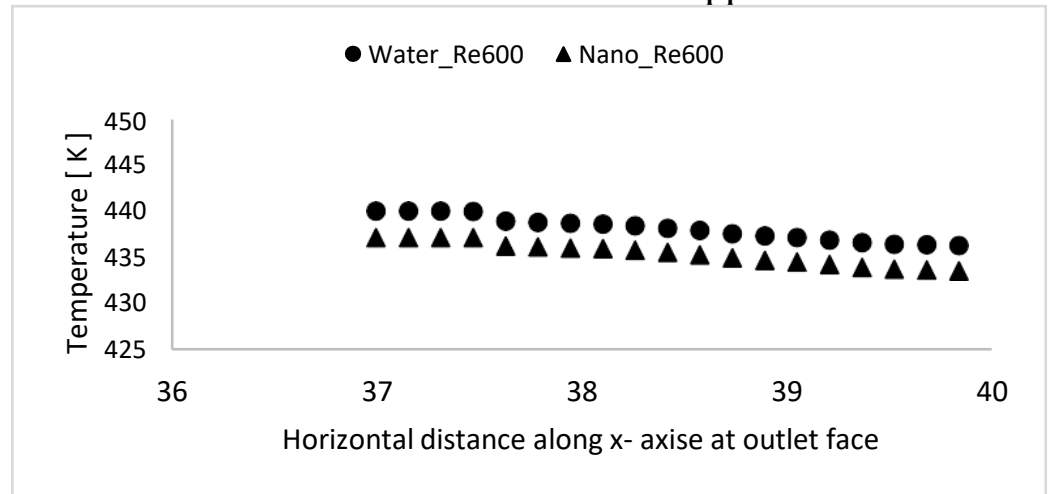

Fig 6. Temperature distribution versus surface outlet pipe at $\mathrm{Re}=600$

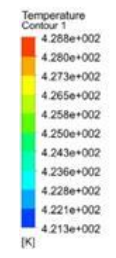
Pure water

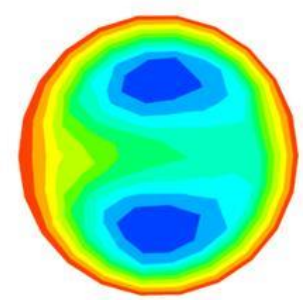

Nanofluid
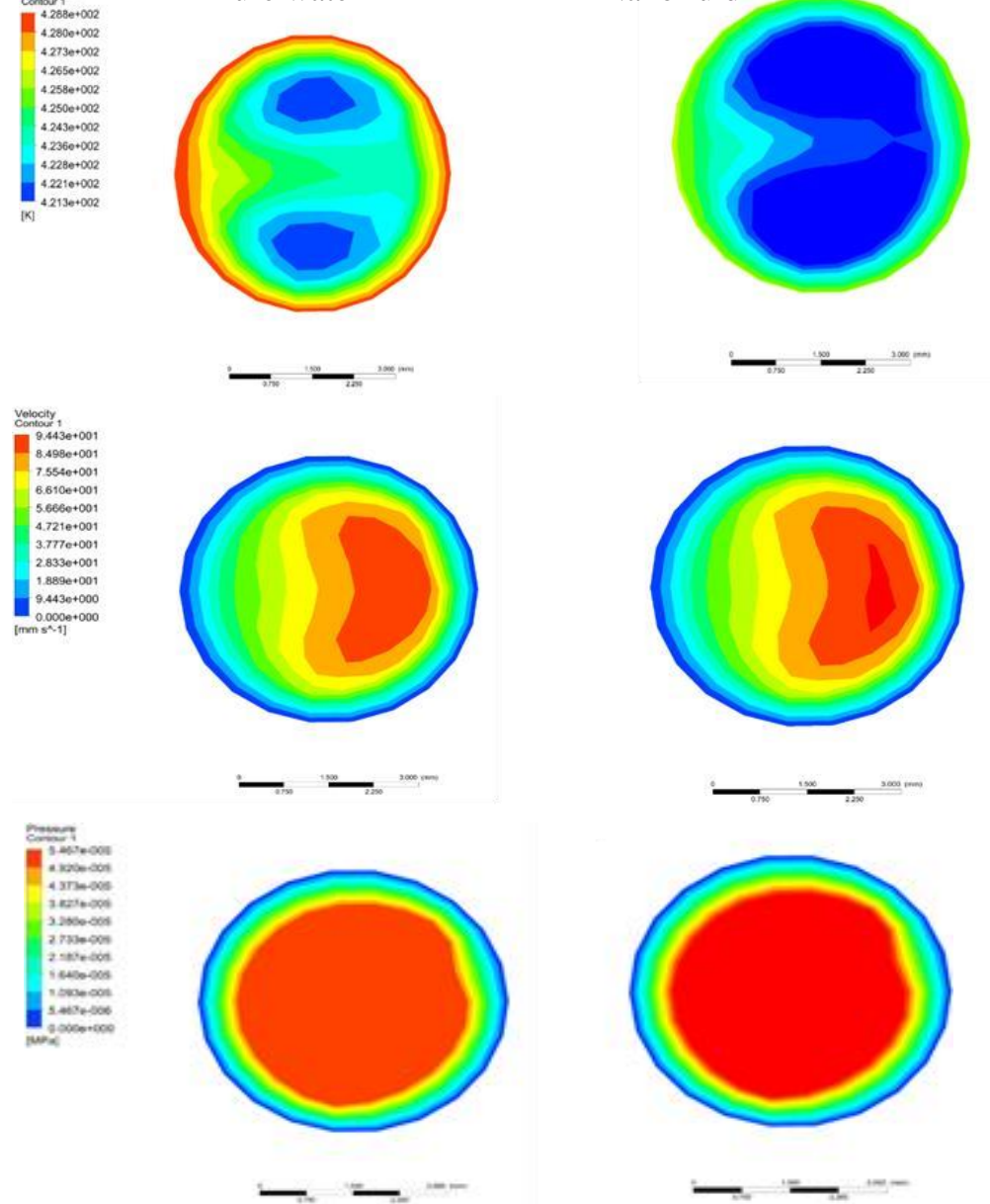

Fig 7. Temperature, velocity, and pressure contours at $\mathrm{Re}=600 \mathrm{using}$ Nano fluid and pure water

Again, Figures 8 and 9 clearly show how the surface temperature reduced linearly as the Reynolds number increased to $\mathrm{Re}=1500$. In general, this temperature reduction is relatively large at $\mathrm{Re}=200$ then becomes smaller when there is a further increase in Reynolds number to
600 and 1500 respectively. For the same concentration, the Reynolds number increases as the temperature increases, and thus the heat transfer reduction range is enlarged.

In summary, compared to the three Reynolds numbers used, the use of $\mathrm{Al} 2 \mathrm{O} 3 /$ water 
Nano fluid gives lower surface pipe temperatures owing to its higher thermal conductivity. Moreover, it was observed, by using Al2O3/water Nano fluid at $\operatorname{Re}=1500$, lower surface temperature $(433 \mathrm{~K})$ is recorded when comparing it to other two Reynolds number having the same Nano fluid (e.g. at Re $=600 \mathrm{~T}=346 \mathrm{~K} ; \operatorname{Re}=200, \mathrm{~T}=722$ respectively). Consequently, as the secondary flow due to the centrifugal forces of circular flow with A12O3/water Nano fluid from 200, 600 , and 1500 respectively, the velocity of the flow increased (see velocity contour Figures). Such increment of the Reynolds number produces secondary flow resulting in lower surface friction and lower temperature. this secondary flow is seen in Figure 9 with double vortices that are symmetrical about the top and bottom halves of the pipe cross-section.

In Figure 11 the relationship between the Reynolds number and heat transfer coefficient can clearly summarize the enhancement of using Nano fluid and further confirmed the results.

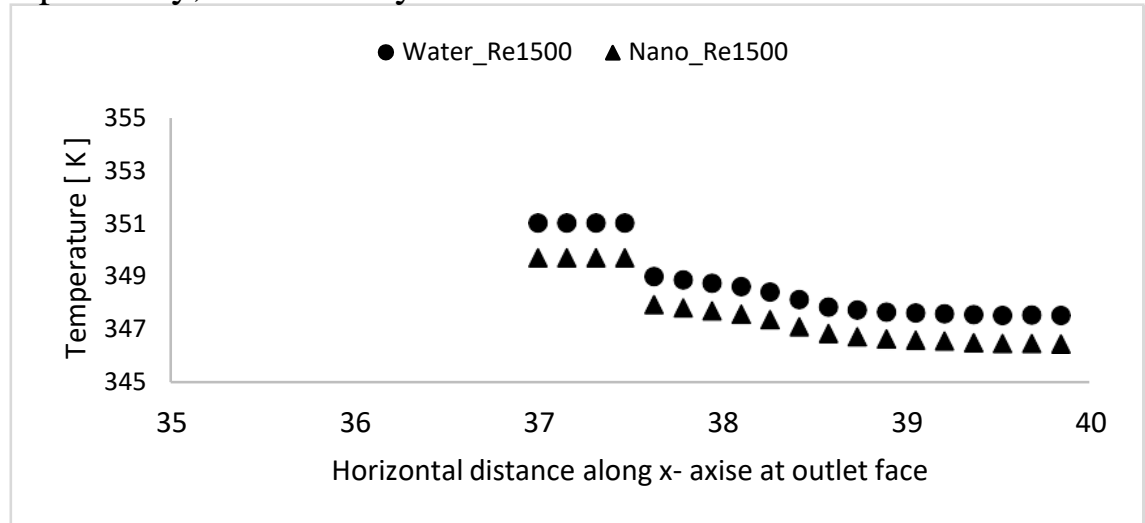

Fig 8. Temperature distribution versus surface outlet pipe at $\mathrm{Re}=1500$

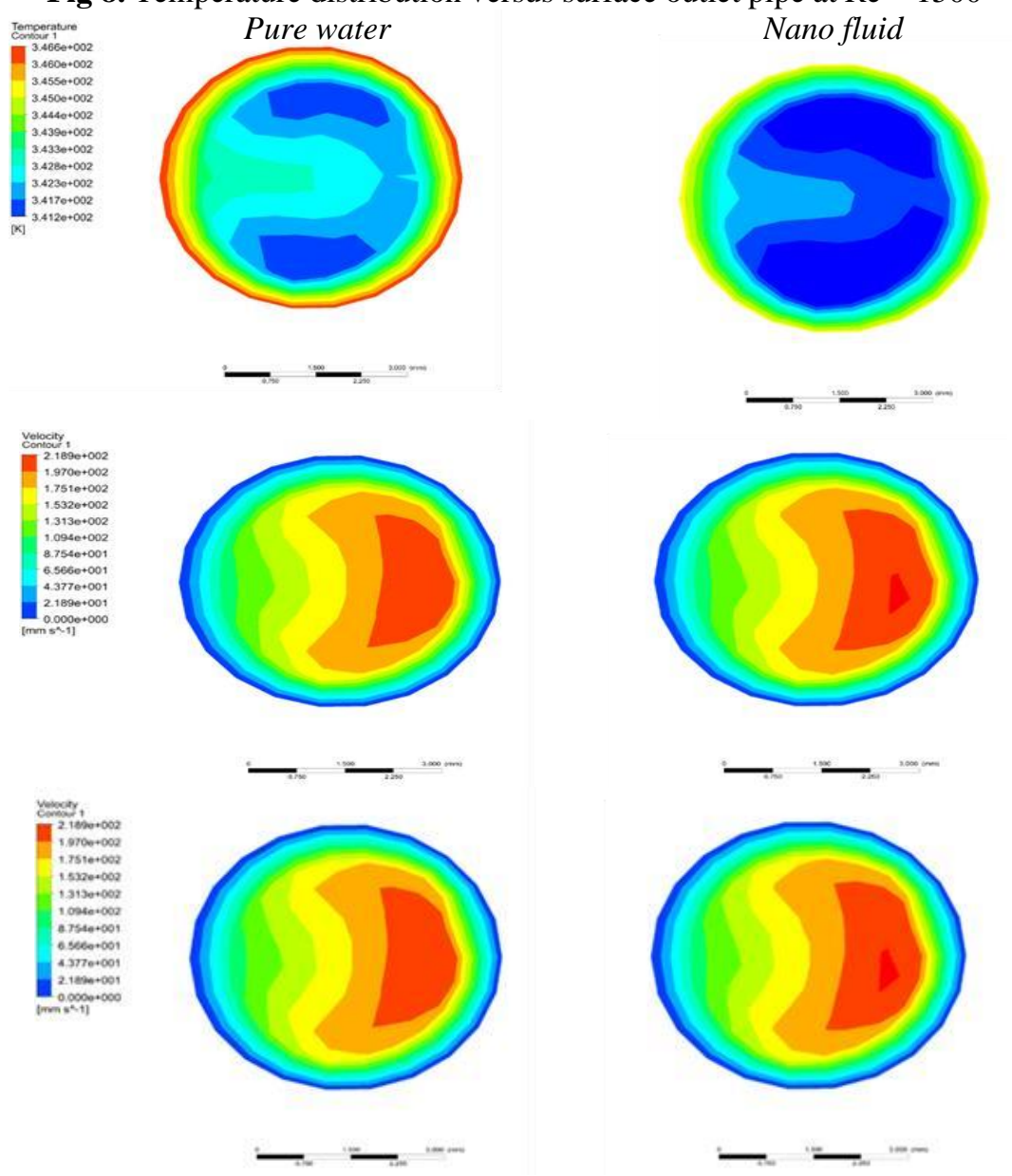

Fig 9. Temperature, velocity, and pressure contours at $\operatorname{Re}=1500$ using Nano fluid 

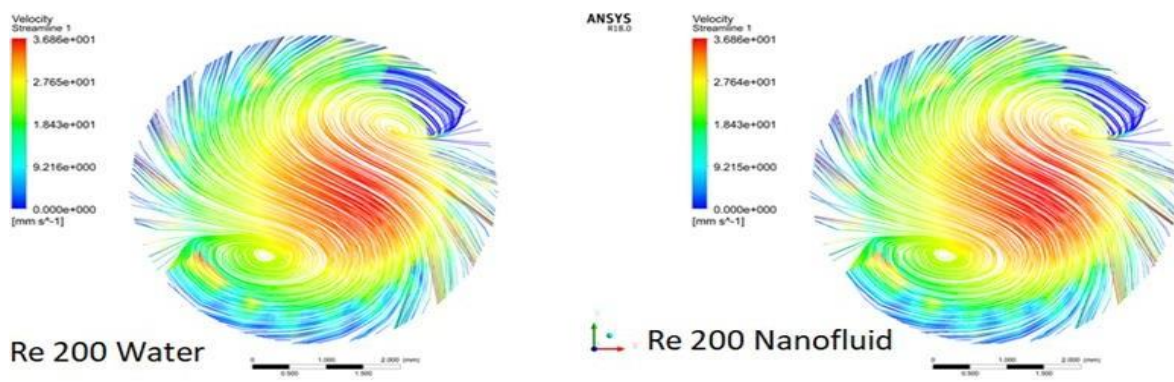

ANsYS
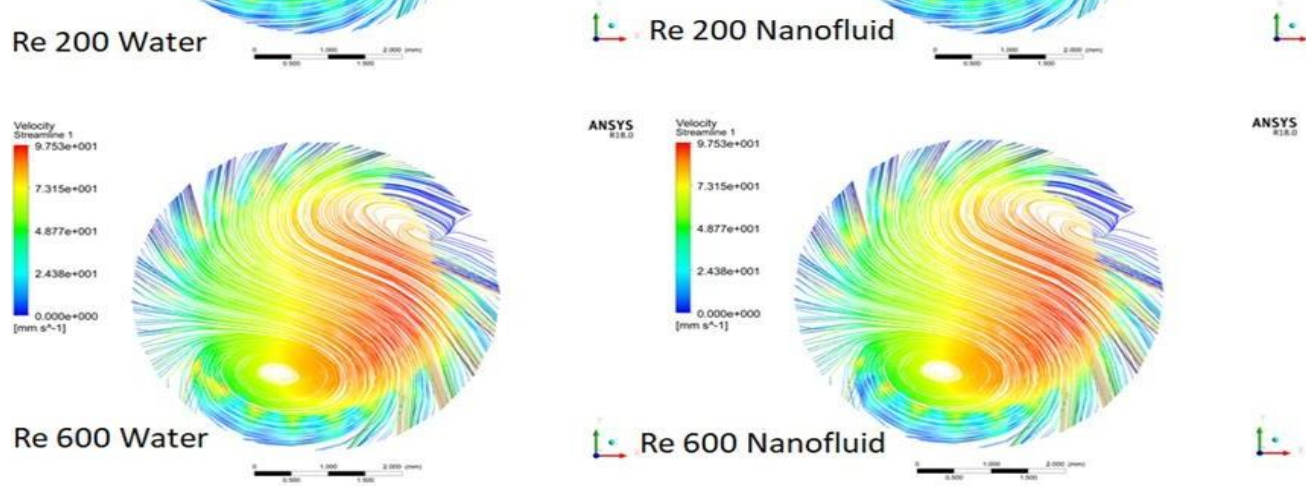

ansYS

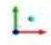

Fig 10. Variation of streamlines on the selected plane before outlet for Re 200 and 600 (water and Nano fluid)

\section{Conclusion}

Two types of familiar cooling liquid (pure water and A12O3/water Nano fluid) were applied in this research to assess the thermal performance in the helically coiled pipe at different Reynolds numbers. Numerical simulation was used to solve continuity, momentum, and energy equations using CFD code. The results showed that both liquids with low Reynolds number $(\operatorname{Re}=200)$ result in a good thermal performance. However, at a high Reynolds number $(\operatorname{Re}=600)$, the temperature distribution is reduced by lower enhancement when Al2O3/water Nano fluid is applied. At the same Reynolds number ( $\operatorname{Re}=600$ ), no huge effect of the Nano fluid on the temperature distribution is seen. The study suggested include a user define functions for Nano fluid properties, such as density and viscosity which need to be temperature-dependent as future work.

\section{References}

[1] Al-Damook, Amer, N Kapur, JL Summers, and HM Thompson. 2016. "Computational design and optimisation of pin fin heat sinks with rectangular perforations." Applied Thermal Engineering no. 105:691-703.

[2] Ali, Faris Mohammed, W Mahmood Mat Yunus, and Zainal Abidin Talib. 2013. "Study of the effect of particles size and volume fraction concentration on the thermal conductivity and thermal diffusivity of A12O3 nanofluids." International Journal of Physical Sciences no. 8 (28):1442-1457.

[3] Ali, Shaukat. 2001. "Pressure drop correlations for flow through regular helical coil tubes." Fluid dynamics research no. 28 (4):295. 
[4] Azari, A, M Kalbasi, and M Rahimi. 2014. "CFD and experimental investigation on the heat transfer characteristics of alumina nanofluids under the laminar flow regime." Brazilian Journal of Chemical Engineering no. 31 (2):469-481.

[5] Bai, Bofeng, Liejin Guo, Ziping Feng, and Xuejun Chen. 1999. "Turbulent heat transfer in a horizontal helically coiled tube." Heat Transfer-Asian Research: Co-sponsored by the Society of Chemical Engineers of Japan and the Heat Transfer Division of ASME no. 28 (5):395-403.

[6] Berger, SA, L Talbot, and LS Yao. 1983. "Flow in curved pipes." Annual review of fluid mechanics no. 15 (1):461-512.

[7] Cioncolini, Andrea, and Lorenzo Santini. 2006. "An experimental investigation regarding the laminar to turbulent flow transition in helically coiled pipes." Experimental Thermal and Fluid Science no. 30 (4):367-380.

[8] De Amicis, Jacopo, Antonio Cammi, Luigi PM Colombo, Marco Colombo, and Marco E Ricotti. 2014. "Experimental and numerical study of the laminar flow in helically coiled pipes." Progress in Nuclear Energy no. 76:206-215.

[9] Duangthongsuk, Weerapun, and Somchai Wongwises. 2010. "An experimental study on the heat transfer performance and pressure drop of TiO2-water nanofluids flowing under a turbulent flow regime." International Journal of Heat and Mass Transfer no. 53 (13):334-344.

[10] Etminan, Amin, Zambri Harun, and Ahmad Sharifian. 2017. Numerical investigation of nanofluid laminar forced convective heat transfer inside an equilateral triangular tube. Paper read at IOP Conference Series: Earth and Environmental Science.

[11] Faraj, A.F. 2016. CFD study of helically coiled pipes with variable pitch, in Faculty of Engineering and Physical Sciences, The University of Manchester UK.

[12] Faraj, Anwer FF, Itimad DJ Azzawi, Samir Gh Yahya, and Amer Al-Damook. 2020. "Computational Fluid Dynamics Investigation of Pitch Variations on Helically Coiled Pipe in Laminar Flow Region." Journal of Heat Transfer no. 142 (10).

[13] Hasan, AF, CJ Bennett, and PH Shipway. 2015. "A numerical comparison of the flow behaviour in Friction Stir Welding (FSW) using unworn and worn tool geometries." Materials \& Design no. 87:1037-1046.

[14] Heris, S Zeinali, Taofik H Nassan, SH Noie, Hamideh Sardarabadi, and Mohammad Sardarabadi. 2013. "Laminar convective heat transfer of $\mathrm{Al} 2 \mathrm{O} 3 /$ water nanofluid through square cross-sectional duct." International Journal of Heat and Fluid Flow no. 44:375-382.

[15] Hussein, Adnan M, RA Bakar, K Kadirgama, and KV Sharma. 2014. "Heat transfer augmentation of a car radiator using nanofluids." Heat and Mass Transfer no. 50 (11):1553-1561.

[16] Jayakumar, JS, SM Mahajani, JC Mandal, Kannan N Iyer, and PK Vijayan. 2010. "CFD analysis of single-phase flows inside helically coiled tubes." Computers \& chemical engineering no. 34 (4):430446.

[17] Kumar, PC Mukesh, and M Chandrasekar. 2019. "CFD analysis on heat and flow characteristics of double helically coiled tube heat exchanger handling MWCNT/water nanofluids." Heliyon no. 5 (7):e02030.

[18] Mahdi, Mustafa S, Ahmed F Hasan, Hameed B Mahood, Alasdair N Campbell, Anees A Khadom, Abdul Mun'em A Karim, and Adel O Sharif. 2019. "Numerical study and experimental validation of the effects of orientation and configuration on melting in a latent heat thermal storage unit." Journal of Energy Storage no. 23:456-468.

[19] Mitrovic, Jovan. 2012. Heat Exchangers: Basics Design Applications: BoD-Books on Demand.

[20] Mori, Yasuo, and Wataru Nakayama. 1967. "Study of forced convective heat transfer in curved pipes (2nd report, turbulent region)." International journal of heat and mass transfer no. 10 (1):37-59.

[21] Rogers, GFC, and YR Mayhew. 1964. "Heat transfer and pressure loss in helically coiled tubes with turbulent flow." International Journal of Heat and Mass Transfer no. 7 (11):1207-1216.

[22] Salman, Sami D, Abdul Amir H Kadhum, Mohd S Takriff, and Abu Bakar Mohamad. 2014. "Heat transfer enhancement of laminar nanofluids flow in a circular tube fitted with parabolic-cut twisted tape inserts." The Scientific World Journal no. 2014.

[23] Seban, RA, and EF McLaughlin. 1963. "Heat transfer in tube coils with laminar and turbulent flow." International journal of heat and mass transfer no. 6 (5):387-395.

[24] Srinivas, T, and A Venu Vinod. 2015. "Heat transfer enhancement using $\mathrm{CuO} /$ water nanofluid in a shell and helical coil heat exchanger." Procedia engineering no. 127:1271-1277.

[25] Ting, Hsien-Hung, and Shuhn-Shyurng Hou. 2015. "Investigation of laminar convective heat transfer for Al2O3-water nanofluids flowing through a square cross-section duct with a constant heat flux." Materials no. 8 (8):5321-5335.

[26] Vajjha, Ravikanth S, and Debendra K Das. 2009. "Experimental determination of thermal conductivity of three nanofluids and development of new correlations." International Journal of Heat and Mass Transfer no. 52 (21-22):4675-4682.

[27] Yarmand, Hooman, Samira Gharehkhani, Salim Newaz Kazi, Emad Sadeghinezhad, and Mohammad Reza Safaei. 2014. "Numerical investigation of heat transfer enhancement in a rectangular heated pipe for turbulent nanofluid." The Scientific World Journal no. 2014. 